\title{
Part III. Can we turn back the clock or modify the adverse dynamics? Programme and policy issues
}

\section{Influencing public nutrition for non-communicable disease prevention: from community intervention to national programme - experiences from Finland}

\author{
Puska Pekka ${ }^{1, *}$, Pietinen Pirjo ${ }^{1,2}$ and Uusitalo Ulla ${ }^{1,3}$ \\ ${ }^{1}$ Department of Noncommunicable Disease Prevention and Health Promotion, World Health Organization, \\ CH-1211 Geneva 27, Switzerland: ${ }^{2}$ National Public Health Institute, Department of Epidemiology and Health \\ Promotion, Helsinki, Finland: ${ }^{3}$ Cornell University, Division of Nutritional Sciences, Ithaca, NY, USA
}

\begin{abstract}
A global health transition is currently underway. The burden of non-communicable diseases (NCDs) is increasing rapidly in the developing world, very much as a result of changes in lifestyles. In addition to changes in tobacco use and physical activity, major changes are taking place in diets, contributing greatly to the growing epidemic of NCD. Thus, a huge global public health challenge is how to influence the trends in diet and nutrition for effective global NCD prevention.

The health transition took place rapidly in Finland after World War II and mortality from cardiovascular disease (CVD) was exceptionally high. The North Karelia Project was launched in 1972 as a community-based, and later as a national, programme to influence diet and other lifestyles that are crucial in the prevention of CVD. The intervention had a strong theory base and it employed comprehensive strategies. Broad community organisation and the strong participation of people were the key elements. Evaluation has shown how the diet (particularly fat consumption) has changed and how these changes have led to a major reduction in population serum cholesterol and blood pressure levels. It has also shown how ischaemic heart disease mortality in a working-age population has declined by $73 \%$ in North Karelia and by 65\% in the whole country from 1971 to 1995.

Although Finland is an industrialised country, North Karelia was rural, of rather low socio-economic level and with many social problems in the 1970s and 1980s. The project was based on low-cost intervention activities, where people's participation and community organisations played a key role. Comprehensive interventions in the community were eventually supported by national activities - from expert guidelines and media activities to industry collaboration and policy. Similar principles for nutrition intervention programmes could be used in developing countries, obviously tailored to the local conditions. This paper discusses the experiences of the North Karelia Project in the light of needs from the less-industrialised countries and makes some general recommendations.
\end{abstract}

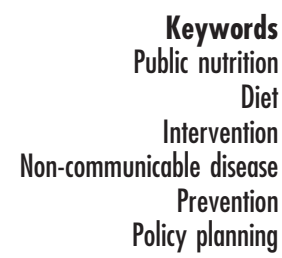

Non-communicable diseases (NCDs) have traditionally been regarded as a problem of the industrialised countries. However, a rapid health transition is taking place in the developing world. Non-communicable diseases and especially cardiovascular diseases (CVDs) have become the major cause of death in most Third World countries ${ }^{1}$. This change is partly due to success in the control of infectious diseases and demographic changes, but is also a consequence of a transition in lifestyles that leads to increased risk of NCDs - nutrition being one of the main determinants ${ }^{2,3}$.
The links between diet, nutrition and chronic diseases are well-established ${ }^{2}$. This particularly concerns CVDs, but also several forms of cancer, diabetes, osteoporosis and oral health. The magnitude of the impact of diet on disease risk and the potential for prevention have been highlighted by recent studies ${ }^{4-7}$. It is quite obvious that changes in diet and nutrition are a major factor in the global disease transition.

The dietary transition in the developing world is very much linked to social and economic changes. Many of these changes relate to globalisation; new food items, new 
marketing methods and new dietary habits have emerged. Social mobility through migration and urbanisation have exposed people to these new foods and encouraged new ways of eating. Consumption of meat, eggs and dairy products has increased while the proportion of starchy staples has declined. Increased consumption of animal products or other high-fat condiments has often compensated for the reduction in staple consumption. Eating outside the home and snacking have become more common. More processed foods with saturated fats have become available for a larger proportion of the population. Increased consumption of energy and fats has often been accompanied by decreased physical activity, which has led to overweight and obesity ${ }^{8-10}$.

It is obvious that influencing public nutrition is a key task in the global strategy for the prevention of $\mathrm{NCDs}^{11}$. This calls for new and innovative strategies and activities at the community, national and global levels. The aim of this paper is to describe the experience of Finland in changing the diet of the population as a part of CVD prevention, and to discuss it in the light of challenges in the developing world.

\section{The nutrition intervention in Finland}

The health transition in Finland in the mid-1900s was rapid. After World War II infectious diseases had become well under control; at the same time the rates of CVD and many cancers increased rapidly. In the early 1970s, the mortality rate from coronary heart disease of Finnish men was the highest in the world ${ }^{12,13}$ and, due to the heavy NCD burden, life expectancy was relatively low. The worst situation was in Eastern Finland, in the province of North Karelia $^{12}$.

When reviewing the situation, it was obvious that the general Finnish diet contributed much to the problem. In the early 1970s, the diet was high in saturated fats, low in unsaturated fats, high in salt, and low in vegetables and fruit $^{14}$. A major community-based intervention, the North Karelia Project, was started in the province of North Karelia as a pilot for national action, in collaboration with the World Health Organization (WHO) ${ }^{15}$. North Karelia was a fairly rural province with some 180000 inhabitants in a rather large area. In the early 1970s, North Karelia was economically poor, with many small dairy farms. There was a shortage of medical resources and many people did not have access to modern services.

The North Karelia Project developed comprehensive community-based strategies to change the general dietary habits ${ }^{16}$. Since elevated blood cholesterol was known as the major risk factor for arteriosclerotic CVD and the local cholesterol levels were extremely high, the main goal of the nutrition programme was to reduce the blood cholesterol levels in the population ${ }^{17}$. The main focus of the strategy was to reduce the high saturated fat intake, especially from dairy sources, and to increase the consumption of vegetables and fruit ${ }^{14}$. Reduction of salt intake was also a key strategic element in order to lower the high blood pressure levels, since the salt intake was found to be high ${ }^{18}$.

A comprehensive intervention was implemented in North Karelia. Objectives and frameworks were designed for the Project, based on epidemiological/medical knowledge and social/behavioural theories. In addition to health information and nutrition counselling, practical skills were taught, social and environmental support was provided, and all sectors of the community were involved ${ }^{16}$.

The Project worked closely with health services (especially primary health care), schools and social services, numerous health-related and other non-government organisations (NGOs), supermarkets and the food industry, various community leaders and the local media. Collaboration with the well-known homemakers' organisation (The MARTTAs) was important. This involved development and distribution of healthier, easy-toprepare recipes. Collaboration with the food industry in reducing and modifying the fat and salt content of commonly eaten foods involved dairies, meat processors, bakeries, and so forth. A berry project was launched to help dairy farmers make a switch to berry farming.

The intervention in North Karelia, although following set objectives and a general framework, was flexible to local situations and to emerging possibilities. Community ownership and people's participation were the key elements in the activities.

After the good results and experiences of the initial 5-year period in North Karelia, the Project started to contribute actively to the national development, while demonstration work in the initial setting in North Karelia continued $^{19}$. Finally, the whole country of Finland was targeted through nation-wide nutrition education, cooperation with the food and catering industry and legislative actions. Currently, the healthcare services, schools and voluntary organisations have the main responsibility in implementing nutrition and health education in Finland. Non-governmental health promotion associations, organisations and charities have founded the Finnish Centre for Health Promotion with 115 members. Many NGOs, such as the Finnish Heart Association, the Finnish Diabetes Association and the Mannerheim League for Child Welfare, have nutrition education as an essential part of their activities ${ }^{20}$. The National Nutrition Council is the governing strategic body in charge of the food and nutrition policy, issuing guidelines and recommendations.

The activities at the national level often referred to the visible experiences from North Karelia. National TV programmes addressing healthy lifestyle were broadcast. The collaboration with the food industry intensified as health promotion became more important in the public agenda. Finally, national policies could be influenced favourably ${ }^{16}$. 
The first large population survey in Finland was accomplished by the Social Insurance Institution in $1969-72^{21}$. The National Public Health Institute (KTL) has continued the surveillance using two methods ${ }^{20}$. First, risk factor surveys on representative samples, every five years, were started in 1972 in Eastern Finland, and also in other parts of the country since 1982 . Dietary surveys have been carried out in connection with most of these surveys $^{22,23}$. Second, postal surveys on health behaviour started biannually in North Karelia in 1972 and annually on a national level since $1978^{24}$.

\section{Results}

The changes in the North Karelian and Finnish diet have been quite remarkable. In the late 1970s, about $60 \%$ of Finns reported using mostly butter on bread, while in 1998 the proportion was only $5 \%$. This contributed significantly to the decrease in saturated fat intake. Soft margarines and butter-oil mixtures as well as low-fat spreads have replaced butter on bread, which used to be the main carrier of fat in the Finnish diet. In 1978, 44\% of men and $35 \%$ of women used fatty milk, whereas in 1998 the respective proportions were only $9 \%$ and $4 \%$. Low-fat milk, for instance, became the standard milk used in schools and in catering as early as the 1970s, and is still the most favoured milk among boys and men. Skimmed milk gained popularity more slowly, but today, girls and women prefer it $^{14,25}$.

While only $1-2 \%$ of people used vegetable oil for cooking in 1972, about $34 \%$ of them reported using mainly vegetable oil in cooking in 1997, and in the urban areas the numbers were even higher ${ }^{25}$. The first study on sodium excretion among elderly men of Eastern and Western Finland showed that mean daily salt intakes were above $15 \mathrm{~g}$ in the East and about $14 \mathrm{~g}$ in the West ${ }^{18}$. The salt intake has slowly decreased in the population, currently averaging about $11 \mathrm{~g}$ in men and $7 \mathrm{~g}$ in women ${ }^{14}$.

As a result of the nutrition programme, the share of saturated fats from energy was decreased from $21 \%$ in 1972 to $14 \%$ in 1997 , and the share of polyunsaturated fats increased from 3.5\% to 5\%, respectively. This has resulted in a substantial increase in the ratio of polyunsaturated to saturated fats ( $\mathrm{P} / \mathrm{S}$ ratio). Also, the energy percentage from total fat decreased from 39\% to 33\%. The share of trans fatty acids from energy was only $0.9 \%$ in men and $0.8 \%$ in women in $1997^{14,20}$.

The dietary changes have been associated with a major decline in the population's cholesterol levels. The serum cholesterol levels of both genders have decreased by $18 \%$ in North Karelia between 1972 and 1997. The cholesterol levels have also decreased markedly in other areas monitored in Finland. At the same time, diastolic blood pressure has decreased by $5 \%$ in men and $13 \%$ in women ${ }^{26}$.
The age-standardised mortality rate of ischaemic heart disease (age group 35-64 years) has decreased by $73 \%$ in North Karelia and by 65\% in the whole country from 1971 to $1995^{12}$. It has been estimated that about $75 \%$ of the decline in mortality from ischaemic heart disease from 1972 to 1992 can be explained by risk factor changes ${ }^{27}$. The major contributor was the reduction in the population cholesterol level, obviously as a result of the previously described dietary changes.

\section{Elements of a successful nutrition programme}

Planning of the project in North Karelia considered that dietary habits are deeply rooted in the cultural and economic features of the community. Thus, the intervention target was the community rather than individuals. It was realised that community organisations with people's own involvement are the key issues. In practice, broadrange action - from media campaigns to collaboration with the food industry to agricultural reforms - was introduced in the Project. A comprehensive evaluation system was also designed that subsequently was developed into a national monitoring system for chronic disease prevention and health promotion ${ }^{16}$.

Long-term and credible nutrition information is a major element in any successful nutrition programme. People not only need information on the links between diet and health, but also clear messages about the practical and culturally appropriate means to change their diet. Education programmes are not only to give information, but also to teach the skills to make the needed changes. Furthermore, good media programmes send persuasive messages through various strategies (e.g. using role models).

These programmes also need long-term support and credible, competent agencies to carry them out. Expertise in nutrition, health and communication skills is needed. Although some centralisation is required for major longterm nutrition education programmes, it should be remembered that multiple message sources are needed and various organisations in the community should be involved. It is very important that the media messages link closely with the ongoing community and policy activities $^{28}$.

An example of a successful component was the intervention to lower the salt intake in the population in North Karelia. It started with the involvement of healthcare personnel and education of the population; later, cooperation with the food and catering industry to lower the sodium content of foods became important ${ }^{29,30}$. Legislature has helped in determining the limits for salt content in low-salt and high-salt products. The law of 1992 lists the maximum salt concentration of soups, sauces and salted mushrooms. It also regulates use of the term 'reduced salt content' on labels, and requires the term 'heavily salted' if 
salt content of the product is above a stipulated level in butter, margarine, sausages, bread and breakfast cereals ${ }^{17}$.

Competitions have been used as positive elements for health promotion concerning, for example, smoking cessation ('quit and win'), physical exercise or diet ${ }^{31}$. North Karelian villages were invited to participate in a cholesterol-lowering competition in 1991 to demonstrate the feasibility of changing their diet and obtaining measurable, positive outcomes. Only a few villages were expected to join in the beginning, but altogether 40 villages wanted to participate. The first competition was among seven villages with good results and set a powerful example to the whole province. The competition was repeated again in 1997; this time 16 villages were included. The mean reduction in cholesterol level was 9\% and, in the winning village, it was 16\%. These reductions were clearly related to self-reported dietary changes ${ }^{16,31}$.

Another innovative intervention example was the berry project. Over the years, many people voiced concerns about the dietary aims of the project in the area, which was initially strongly devoted to dairy farming. With people sharply reducing their consumption of butter and fatty dairy products, economic problems emerged for dairy farmers and the dairy industry. People were also unsatisfied with the message promoting the consumption of products that were mostly imported, such as fruit and vegetables. During these discussions, the community and Project representatives considered the feasibility of growing tasty, nutritious berries in the northern climate. This led to a major collaborative project between berry farmers, industry, various commercial sectors and the health authorities, which was financed by the Ministry of Agriculture and the Ministry of Commerce. Sales campaigns, new product development and various supportive activities were also involved, in addition to education. Local berry consumption rose gradually, and many farmers switched from dairy to berry production $^{16,32}$.

Liberalisation of regulations on dietary fats has made it possible to manufacture novel fat spreads by mixing dairy fats and vegetable oils, as well as low-fat spreads. This has prompted an innovative variety of low-fat spreads, which have grown immensely popular among the Finnish population. In response to the evolving health consciousness among its customers, the Finnish food industry has pursued the development of new low-fat products with great diligence and creativity. In the 1980s, low-fat milks and fat spreads promoted by the Project were joined by low-fat cheeses, ice creams, sausages, etc. ${ }^{17}$. A specific innovation was the development of a plant-sterolcontaining margarine, which was very effective in lowering blood cholesterol. This product was studied carefully in a large trial in North Karelia ${ }^{33}$.

Increasing the availability and marketing of 'hearthealthy' choices made it much easier for people to comply with the health message. The quality of meat has changed dramatically over the past decades, with lean pork largely replacing fatty pork and beef. Food preparation methods also started to favour boiling and cooking with little or no fat $^{19}$.

Another very significant associated development took place in the 1980s. A new type of rape plant was developed that grew well in the northern climate of Finland. It was shown that this type of rapeseed oil (Canola oil) was very effective in lowering cholesterol. For the first time there was a domestic heart-healthy fat alternative, which helped to smooth the battle between 'domestic dairy fat' and 'imported vegetable fat'. The new oil products quickly became quite popular and cooking with vegetable oil - in moderate amounts - became fashionable in Finnish kitchens ${ }^{19}$.

In connection with the Finnish membership in the European Union, reforms were made that helped neutralise the taxation burden between dairy and vegetable oil fats (previously dairy fats were favoured). Unfortunately, the European Union has at the same time brought some new problems such as its policy to subsidise the use of fatty milk at school lunches but not skimmed milk ${ }^{19}$.

Developing a national food and nutrition policy, as experienced in Finland, is ultimately a matter of a long social change process as presented in Fig. 1. Scientific

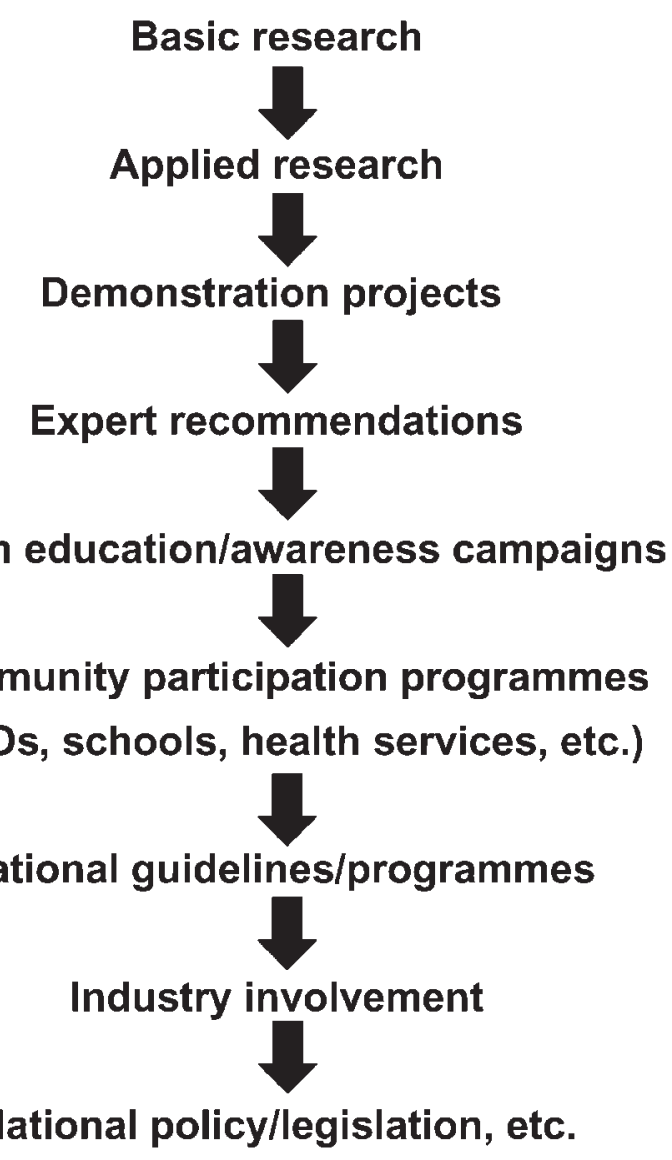

Fig. 1 From research to public policy ${ }^{28}$ 
evidence based on basic and applied research is the starting point. Demonstration projects in communities and other settings show how respective changes can be implemented in real life.

After the evidence and development of feasible methods, expert groups and governmental committees give their recommendations about healthy diets. The first to respond to the new medical knowledge are often active health organisations, like heart associations. They launch awareness campaigns - to make people aware of the links (e.g. between diet, cholesterol and heart disease) and of the possibilities to act upon this knowledge.

Gradually, more and more partners in the community/society respond and start to participate in the action. This concerns other NGOs and also health services, schools, workplaces, and so forth. The action includes, for example, various kinds of health education, screening programmes and patient consulting. With increased interest of the public (i.e. consumers), the food industry starts to respond. The industry sees that there is a market (e.g. for cholesterol-lowering food items) and health claims have an increased weight in marketing.

Usually at a rather late stage of this development, policy, decisions and legislation become feasible and useful to strengthen the change process. Because of conflicting interests, public administration usually works slowly and major decisions are made only when the change process has progressed rather far. Politicians are not so much influenced by expert statements as they are by feedback from their constituency ${ }^{28}$.

\section{Implications for developing countries}

Although North Karelia belongs to the industrialised part of the world, we must remember that it was earlier very rural, of rather low socio-economic level and with many social problems. Therefore, the methods that were chosen and described were low-cost, community-based intervention activities that are largely based on people's own participation and community organisations. Thus, the experiences are of relevance to many other countries including the developing nations.

One could argue that the main principles of communitybased and national NCD prevention programmes are universal. This concerns both the medical evidence (e.g. high blood pressure, high cholesterol and obesity) and some principles of human behaviour and social sciences. It also concerns well-established principles of programme planning, implementation, monitoring and evaluation. At the same time, it is vital that each country and community find its own solutions. The interventions must be tailored to the local culture.

The principles of the intervention are universal: defining the population base, defining the different level of objectives, planning the framework of activities, and planning the monitoring and evaluation. An example of a country with a successful nutrition policy and education intervention is Mauritius, where, during a five-year intervention, a remarkable effect was observed in the diet and in the serum cholesterol level ${ }^{34,35}$.

The monitoring system is vital to assess the baseline situation for planning purposes and for monitoring of changes in the community and nation-wide. Each country has to develop its own appropriate monitoring activities after recognising the main problems and the target groups for the interventions. Simple and rapid monitoring of target dietary behaviours (health behaviour monitoring) has proven to be an important intervention tool.

Sharing the experiences with other countries will provide valuable feedback. It will also help in successful planning and in avoiding costly mistakes in those countries that are about to start dietary intervention programmes. It will also facilitate and contribute in strengthening the international and global actions. That is why present WHO programmes very much emphasise collaboration through international networks such as CARMEN (Conjunto de Acciones para la Reduccion Multifactorial de Enfermedades No transmisibles) in Latin America and the CINDI (Countrywide Integrated Noncommunicable Disease Intervention) programme in Europe.

Based on the experiences from North Karelia and Finland, the following summary of conclusions and recommendations can be drawn.

- Community health programmes should pay attention to the well-established principles and rules of general programme planning, implementation and evaluation.

- Preventive community programmes should be concerned with both appropriate medical/nutritional frameworks to select the intermediate objectives, and with relevant behavioural/social theories in designing the actual programme.

- Good understanding of the community ('community diagnosis'), close collaboration with various community organisations and full participation of the people should be essential elements of intervention programmes.

- Community intervention programmes should combine well-planned media and communication messages with broad-ranged community activities involving primary health care, voluntary organisations, food industry and supermarkets, work sites, schools and local media.

- Community intervention programmes should seek collaboration and support from both formal community decision-makers and informal opinion leaders.

- Community intervention programmes should combine sound theoretical frameworks with dedication, persistence and hard work to be successful.

- Attempts to change social and physical environments in the community to be more conducive to health and healthy lifestyles should be a major emphasis and strength of a community intervention programme. 
- Proper evaluation should be carried out and results disseminated concerning major community intervention programmes. These community programmes can be useful for a target community, but can also have broader impact as a national demonstration programme.

- The project, for national implications, should work in close contact with national health policy-makers throughout the programme.

\section{Conclusions}

It is concluded that theory-based comprehensive interventions in the community can meaningfully influence the diet and transition in the population, and that such changes can influence the CVD rates surprisingly rapidly. The experiences from North Karelia and Finland, although from the industrialised world, are relevant for the contemporary challenges in the developing world to counteract the health transition (i.e. the rapid increase in some NCDs). Comprehensive community-level demonstration programmes can be useful tools in ultimately influencing national policies and promoting a healthy social change. In the fight against the growing epidemic of NCDs with their tremendous economic consequences and burdens to health services, population-based nutrition programmes have a great potential to be the most costeffective way to prevent premature mortality and morbidity and to promote the health of people.

\section{References}

1 Murray CJL, Lopez AD. Mortality by cause for eight regions of the world: Global Burden of Disease Study. Lancet 1997; 349: 1269-76.

2 World Health Organization (WHO). Diet, Nutrition, and the Prevention of Chronic Diseases. Report of a WHO Study Group. Technical Report Series 797. Geneva: WHO, 1990.

3 Michaud CM, Murray CJL, Bloom BR. Burden of disease implications for future research. JAMA 2001; 285: 535-9.

4 Tuomilehto J, Lindström J, Eriksson J, Valle TT, Hämäläinen H, Ilanne-Parikka P, Keinänen-Kiukaanmäki S, Laakso M, Louheranta A, Rastas M, Salminen V, Uusitupa M. Prevention of type 2 diabetes mellitus by changes in lifestyle among subjects with impaired glucose tolerance. N. Engl. J. Med. 2001; 344: 1343-50.

5 Hu FB, Manson JE, Stampfer MJ, Colditz G, Liu S, Solomon CG, Willett WC. Diet, lifestyle, and the risk of type 2 diabetes mellitus in women. N. Engl. J. Med. 2001; 345: 790-7.

6 McCullough ML, Feskanish D, Rimm EB, Giovannucci EL, Ascherio A, Variyam JN, Spiegelman D, Stampfer MJ, Willett WC. Adherence to the Dietary Guidelines for Americans and risk of major chronic disease in men. Am.J. Clin. Nutr. 2000; 72: $1223-31$.

7 McCullough ML, Feskanish D, Stampfer MJ, Rosner BA, Hu FB, Hunter DJ, Variyam JN, Colditz GA, Willett WC. Adherence to the Dietary Guidelines for Americans and risk of major chronic disease in women. Am. J. Clin. Nutr. 2000; 72: 1214-22.

8 Drewnowski A, Popkin BM. The nutrition transition: new trends in the global diet. Nutr. Rev. 1997; 55: 31-43.
9 Sobal J, Stunkard AJ. Socioeconomic status and obesity: a review of the literature. Psychol. Bull. 1989; 105: 260-75.

10 Sobal J. Food system globalization, eating transformations, and nutrition transitions. In: Grew R, ed. Food in Global History. Boulder, CO: Westview Press, 1999; 171-93.

11 Ramalingaswami V. Diseases of affluence. World Health 1992; (Nov-Dec): 24.

12 Puska P, Vartiainen E, Tuomilehto J, Salomaa V, Nissinen A. Changes in premature deaths in Finland: successful longterm prevention of cardiovascular diseases. Bull. World Health Org. 1998; 76: 419-25.

13 Ovcarov V, Bystrova V. Present trends in mortality in the age group 35-64 in selected developed countries between 1950-73. World Health Stat. Quart. 1978; 31: 208.

14 Pietinen P, Lahti-Koski M, Vartiainen E, Puska P. Nutrition and cardiovascular disease in Finland since the early 1970s: a success story. J. Nutr. Health Aging 2001; 5: 150-9.

15 Puska P, Tuomilehto J, Salonen J, Nissinen A, Virtamo J, Björkqvist S, Koskela K, Neittaanmäki L, Takalo L, Kottke TE, Mäki J, Sipilä P, Varvikko P. The North Karelia Project: Evaluation of a Comprehensive Community Programme for Control of Cardiovascular Diseases in North Karelia, Finland 1972-1977. Copenhagen: World Health Organization European Office, 1981.

16 Puska P, Tuomilehto J, Nissinen A, Vartiainen E, eds. The North Karelia Project. 20 Year Results and Experiences. Helsinki: University Press, 1995.

17 Pietinen P, Vartiainen E. Dietary changes. In: Puska P, Tuomilehto J, Nissinen A, Vartiainen E, eds. The North Karelia Project. 20 Year Results and Experiences. Helsinki: University Press, 1995; 107-17.

18 Karvonen MJ, Punsar S. Sodium excretion and blood pressure of west and east Finns. Acta Med. Scand. 1977; 202: 501-7.

19 Puska P. Nutrition and mortality: the Finnish experience. Acta Cardiol. 2000; 55: 213-20.

20 National Public Health Institute (KTL). Nutrition in Finland. KTL Publication. Helsinki: KTL, 1999.

21 Hasunen K, Pekkarinen M, Koskinen E, Seppänen R, Beckström LA. The Food Consumption and Nutrient Intake in Finland from 1969 to 1972. Report B8/1998. Helsinki: Social Insurance Institution, 1998 [in Finnish with an English summary].

22 Pietinen P, Uusitalo U, Vartiainen E, Tuomilehto J. Dietary survey of the FINMONICA project in 1982. Acta Med. Scand. Suppl. 1988; 728: 169-77.

23 Pietinen P, Vartiainen E, Seppänen R, Aro A, Puska P. Changes in diet, in Finland from 1972-1992; impact on coronary heart disease. Prev. Med. 1996; 25: 243-50.

24 Helakorpi S, Puska P. Health behaviour changes in North Karelia. In: Puska P, Tuomilehto J, Nissinen A, Vartiainen E, eds. The North Karelia Project. 20 Year Results and Experiences. Helsinki: University Press, 1995; 141-56.

25 Helakorpi S, Uutela A, Prättälä R, Puska P. Health Behaviour Among Finnish Adult Population. Publication B10/1998. Helsinki: National Public Health Institute, 1998.

26 Vartiainen E, Jousilahti P, Alfthan G, Sundvall J, Pietinen P, Puska P. Cardiovascular risk factor changes in Finland, 1972-1997. Int. J. Epidemiol. 2000; 29: 49-56.

27 Vartiainen E, Puska P, Pekkanen J, Tuomilehto J, Jousilahti P. Changes in risk factors explain changes in mortality from ischaemic heart disease in Finland. Br. Med. J. 1994; 309: 23-7.

28 Puska P. Development of public policy on the prevention and control of elevated blood cholesterol. Cardiovascular Risk Factors 1996; 6: 203-10.

29 Nissinen A, Pietinen P, Tuomilehto J, Tanskanen A, Moisio S, Puska P. Experiments with dietary intervention in hypertension control - implementation of the North Karelia Salt project. Magnesium 1982; 1: 232-40. 
30 Tuomilehto J, Puska P, Tanskanen A, Karppanen H, Pietinen P, Nissinen A, Enlund H, Ruotsalainen P. A community-based intervention study on the feasibility and effects of the reduction in salt intake in North Karelia. Acta Cardiol. 1981; 36: $83-104$.

31 Puska P, Isokääntä M, Korpelainen V, Vartiainen E. Village competition as an innovative method for lowering population cholesterol. Eur. Heart J. 1999; 1(Suppl. S): S64-S72.

32 Kuusipalo J, Mikkola M, Moisio S, Puska P. The East Finland berry and vegetable project: a health-related structural intervention programme. Health Promotion 1986; 1: 385-91.

33 Miettinen TA, Puska P, Gylling H, Vanhanen H, Vartiainen E. Reduction of serum cholesterol with sitostanol-ester margarine in a mildly hypercholesterolemic population. N. Engl. J. Med. 1995; 333: 1308-12.

34 Dowse GK, Gareeboo H, Alberti KGMM, Zimmet P, Tuomilehto J, Purran A, Fareed D, Chitson P, Collins VR, Hemraj F. Changes in population cholesterol concentrations and other cardiovascular risk factor levels after five years of the non-communicable disease intervention programme in Mauritius. Br. Med. J. 1995; 311: 1255-9.

35 Uusitalo U, Feskens EJM, Tuomilehto J, Dowse G, Haw U, Fareed D, Hemraj F, Gareeboo H, Alberti KGMM, Zimmet P. Fall in total cholesterol concentration over five years in association with changes in fatty acid composition of cooking oil in Mauritius: cross sectional survey. Br. Med. J. 1996; 313: 1044-6. 